\title{
Correction to: The effects of a novel herbal toothpaste on salivary lactate dehydrogenase as a measure of cellular integrity
}

\author{
Prem K. Sreenivasan ${ }^{1} \cdot$ Veera Venkata Prasad Kakarla ${ }^{2}$ (D) Shweta Sharda $^{2} \cdot$ Yogitha Setty $^{2}$ \\ Published online: 26 October 2020 \\ (C) Springer-Verlag GmbH Germany, part of Springer Nature 2020
}

\section{Correction to: Clinical Oral Investigations. https://doi.org/10.1007/s00784-020-03623-8}

In the original version of this article, the following were noted for correction.

1. A symbol If as shown in Table 3 needs to be included in Tables 4 and 5.

2. The section under the header "Discussion" in paragraph 9 is edited for clarity.

The correct presentation is below:

Oral LDH levels in the control group decreased over the study period; however, the effects of the test group were substantially higher. The test group consistently demonstrated statistically significant reductions from the control with a $9.5 \%$ noted after 3 weeks that increased to $13 \%$ at 6 weeks and $15 \%$ at 12 weeks.

3. Table 1: The Gender in column 1 needs a dedicated symbol and needs to be applied to the gender sentence and in the foot note.

The original article has been corrected.

Publisher's note Springer Nature remains neutral with regard to jurisdictional claims in published maps and institutional affiliations.

The online version of the original article can be found at https://oi.org/ $10.1007 / \mathrm{s} 00784-020-03623-8$

Veera Venkata Prasad Kakarla

kakarlap@hotmail.com

1 Department of Oral Biology, Rutgers School of Dental Medicine, Newark, NJ 07103, USA

2 Public Health Dentistry SDM College of Dental Sciences and Hospital SDM College of Dental Sciences \& Hospital, Affiliated to SDM University, Dharwad, Karnataka, India 